\title{
A Pre-Post Intervention-Based Study Investigating the Impact of Standardized Parenteral Nutrition at Tertiary Neonatal Intensive Care Unit in Karachi, Pakistan
} Vikram Kumar ${ }^{1}$, Anum Rahim ${ }^{2}$, Erum Choudry ${ }^{3}$, Rafia Jabbar ${ }^{4}$, Waqar H. Khowaja ${ }^{5}$, Shabina Ariff ${ }^{5}$,
Syed Rehan Ali ${ }^{1}$

1. Neonatology, Indus Hospital and Health Network, Karachi, PAK 2. Indus Hospital Research Center, Indus Hospital and Health Network, Karachi, PAK 3. Indus Hospital and Research Center, Indus Hospital and Health Network, Karachi, PAK 4. Pediatrics, Indus Hospital and Health Network, Karachi, PAK 5. Pediatrics and Child Health, Aga Khan University Hospital, Karachi, PAK

Corresponding author: Syed Rehan Ali, rehan.ali@tih.org.pk

\section{Abstract \\ Introduction}

Conventionally, various parenteral nutrition (PN) components are individually administered considering an individual neonate's requirements. More recently, standardized PN (SPN) formulations have been initiated for preterm neonates, which may benefit from the enhanced nutrient supply, less administration and prescription errors, reduced risk of infectious disease, and cost-effectiveness.

\section{Methodology}

A multicentered, pre-post intervention-based study was conducted at tertiary neonatal intensive care units (NICUs) in Karachi, Pakistan. Post-graduate residents of neonatology and pediatrics working in NICUs were included in the study, and their perspective was attained regarding PN formulation and a prescription for time consumption, ease, calculation errors, and general feedback. Independent T-test was applied to assess the statistical difference between the pre-and post-implementation of PN formulation for total time required for PN calculation, whereas for the rest of the quantitative variables Mann-Whitney U test was computed.

\section{Results}

The total time required to do the entire writing process, calculating and ordering PN, was $17.1 \pm 6.9$ whereas significantly ( $p$-value of $<0.0001$ ) reduced to $10.5 \pm 5.7$ after implementing SPN prescriptions. Calculation errors were reduced from $32 \%$ to $12 \%$, and writing errors were also decreased from $35 \%$ to $8 \%$ when the standardized parenteral nutritional formulation was applied.

Review began 05/03/2021 Review ended 05/17/2021 Published 05/25/2021

๑) Copyright 2021

Kumar et al. This is an open access article distributed under the terms of the Creative Commons Attribution License CC-BY 4.0., which permits unrestricted use, distribution, and reproduction in any medium, provided the original author and source are credited.

\section{Conclusion}

Our findings show that implementing standardized prescriptions in the NICU has improved medication safety, with the most consistent benefit by reducing medication errors and time management. The SPN prescriptions save time for post-graduate residents, physicians, and pharmacists by eliminating previously required repetitive activities and calculations.

Categories: Pediatrics, Pediatric Surgery, Quality Improvement

Keywords: neonatology, standardized parenteral nutrition, parenteral nutrition, individualized parenteral nutrition, nicu

\section{Introduction}

Nutrition is necessary for all living things for routine needs of the body, development, and growth. Balanced nutrition in early life has a long-term impact on growth, development metabolism, and general health [1]. Prematurely born neonates are critical and not ready to suck, swallow, assimilate, and absorb their diet properly [2]. Their gastrointestinal tract is not mature enough to tolerate direct full feed, so they are fed on gradual enteral nutrition [3]. Due to limited energy supply through enteral nutrition, an alternative source of nutrition and energy parenteral nutrition (PN) is provided, which helps transition from minimal to full enteral nutrition to fulfill body requirements [4].

Parenteral nutrition is an essential part of the management of premature infants with very low birth weight (VLBW) admitted to neonatal intensive care units (NICUs). PN constitutes macronutrients, micronutrients, minerals, and trace elements; these are combined in different ways to provide adequate energy and optimal 
recommended daily intake (RDI) [5]. If appropriate nutrition is not provided as per RDI, it may lead to growth failure, affect the neurodevelopmental outcome, and cause morbidities [6].

Manufacturing an intravenous composition of PN needs multiple stable components of predefined concentration in the appropriate amount to ensure the optimal provision. The mixture must be composed under aseptic measures to avoid infection risks. Its complex nature, specifications, and appropriateness make it a high-risk therapy [7,8]. Due to the complex nature of PN composition, there are multiple chances of errors during its compounding that can compromise neonatal safety and health [9].

For better quality achievement and reduced errors, the American Society of Enteral and Parenteral Nutrition (A.S.P.E.N) published guidelines for parenteral nutrition ordering, order review, compounding, labeling, and dispensing [10]. Studies have reported that standardized parenteral nutrition (SPN) is relatively safe, costeffective, and provides adequate nutrition with fewer chances of errors. It provides more calories than individualized parenteral nutrition (IPN) and increases amino acid, calcium, and phosphate intake while reducing early weight loss [11-13].

To determine the impact of SPN formulation and prescription for neonates at a tertiary NICU in Karachi, we adopted the Australian group consensus 2012 to SPN practices for neonates [14]. We implemented the SNP protocol for neonates in NICUs in two major tertiary care hospitals in the city, named Aga Khan University Hospital (AKUH) and Indus Hospital and Health Network (IHHN), Karachi, Pakistan. The main objective of this study was to assess the benefits of SPN in terms of calculation errors, prescription errors, and time management before and after implementation in the NICU.

\section{Materials And Methods \\ Study setting and population}

From June 2020 to September 2020, a pre-post intervention study was conducted at a tertiary NICU of the IHHN and AKUH, Karachi, Pakistan. Post-graduate residents of neonatology and pediatrics posted in the NICU were included in the study. After obtaining the ethical approval from the Institutional Review Board (IRD_IRB_2020_06_004), a survey was designed on REDCap to gather information regarding the level of trainees, their perspectives regarding PN formulation, general feedback, and difficulty level. The prescriptions were also assessed for time consumption, ease, and errors.

The project was initially implemented at AKUH, a Joint Commission International (JCI) accredited hospital in Karachi, Pakistan, and has a level 3 NICU comprising 24 beds. The annual birth rate is around 5000, out of which 16-17\% are born prematurely. Annual NICU admissions are 1200-1300/year. Later, the protocol was replicated with success at IHHN, Karachi, which comprises a 12 bedded level 3 tertiary care NICU with 700800 births/year.

\section{Pre-intervention phase}

Prescription and Calculation of $P N$

In the pre-implementation phase, the assigned resident reviewed the need for PN with a team of attending physicians, followed by calculations for different constituents of PN, keeping in view the recommended dietary allowance (RDA) and the most recent biochemical profile of the admitted infant. After a thorough review of each calculation, a prescription request to the pharmacy was generated; this exercise had to be repeated daily. The concentration of all the ingredients had to be changed on different days depending upon the patient's daily fluid balance, most recent biochemical profile, and blood sugar status. This was followed by writing on the prescription paper for the nurses.

PN Pharmacy Review Process

The pharmacist received PN requests through the hospital software; counterchecked each calculation while reviewing the biochemical profile of the infant via Patient Profile Viewer (PPV). If the pharmacist deemed any necessary modifications to be made, he communicated it with the concerned physician on the telephone. Subsequently, the request was then sent to the PN technician for formulation.

PN Reviewed by the Nurse

Once the PN bag arrived from the pharmacy, the inpatient nurse matched the label with the prescription before starting the nutrition through a parenteral route.

\section{Post-intervention phase}

Standardization of PN for Neonates

A standardized protocol for PN was implemented at the AKUH and IHHN after the approval from the 


\section{Cureus}

hospital's nutrition committee, pharmacy, and drug committee. This protocol included three standards (starter, standard term, and standard preterm) and two optional (high sodium, low glucose) standards PN. Following were the important agenda points approved by the nutrition committee:

1. To standardize PN indication in NICU as every preterm, irrespective of gestational age, should receive PN.

2. To develop five different categories of PN.

2.a. Three standards: (i) Standard starter PN for the first 24 hours after birth and can be used later for babies with hyperkalemia or renal failure with fluid restriction. (ii) Standard preterm PN for preterm neonates after the first 24 hours of life. (iii) Standard term PN for term neonates after the first 24 hours of life.

2.b. Two optional standards according to biochemical profiles of neonates: (i) Standard high sodium PN for neonates with hyponatremia. (ii) Standard low glucose PN for neonates with hyperglycemia. (iii) Uniform standard of practice was established constituting the following points: (1) Indication criteria for PN administration (as illustrated in Table 1). (2) Ingredient and constituent for different categories of PN for pharmacists as a standard reference document shown in Table 2. (3) Provision of nutrients and electrolytes per kg per day at different rates of PN infusion for better understanding of physicians, residents, and nurses. (4) Biochemical and clinical conditions which warrant SPN, then the infant can be switched to IPN (Table 3).

(5) A standard biochemical profile monitoring schedule was also developed as shown in Table 4.

Indications

Preterm birth (<32 weeks gestation)

Preterm baby with birth weight $<1200 \mathrm{~g}$

Malabsorption syndrome

Suspected/confirmed necrotizing enterocolitis

Any clinical condition which causes a delay in enteral feeding

Having evidence of perinatal asphyxia

Intrauterine growth retardation with absence or reversal of diastolic flow in the umbilical artery

Any neonate unable to achieve full feed by the fifth day of life

TABLE 1: Indications for parenteral nutrition administration 


\section{Cureus}

\begin{tabular}{|c|c|c|c|c|c|c|}
\hline \multicolumn{7}{|l|}{ Constituent per $100 \mathrm{ml}$} \\
\hline \multirow[b]{2}{*}{ Ingredients with concentration } & \multirow{2}{*}{$\begin{array}{l}\text { Age } \\
\text { Category }\end{array}$} & \multirow{2}{*}{$\begin{array}{l}\text { At birth } \\
\text { Starter }\end{array}$} & \multicolumn{2}{|c|}{ After 24 hours of life ${ }^{\star \star}$} & \multicolumn{2}{|l|}{ Optional } \\
\hline & & & $\begin{array}{l}\text { Standard } \\
\text { preterm }\end{array}$ & $\begin{array}{l}\text { Standard } \\
\text { term }\end{array}$ & $\begin{array}{l}\text { Low } \\
\text { glucose }{ }^{\star \star \star}\end{array}$ & high sodium ${ }^{\star \star \star \star}$ \\
\hline \multicolumn{2}{|l|}{ Proteins (10\% amino) } & \multicolumn{5}{|c|}{$25 \mathrm{ml}=2.5 \mathrm{~g} / 100 \mathrm{ml}$} \\
\hline \multicolumn{2}{|l|}{ Dextrose percentage } & $\begin{array}{l}8 \mathrm{~g} / 100 \\
\mathrm{ml}\end{array}$ & $\sim 8 \mathrm{~g} / 100 \mathrm{ml}$ & $\begin{array}{l}\sim 10 \mathrm{~g} / 100 \\
\mathrm{ml}\end{array}$ & $\begin{array}{l}\sim 7 \mathrm{~g} / 100 \\
\mathrm{ml}\end{array}$ & $7.8 \mathrm{~g} / 100 \mathrm{ml}$ \\
\hline \multicolumn{2}{|l|}{$25 \%$ dextrose } & $6 \mathrm{ml}$ & $12 \mathrm{ml}$ & $25.3 \mathrm{ml}$ & $6.3 \mathrm{ml}$ & $12 \mathrm{ml}$ \\
\hline \multicolumn{2}{|l|}{$10 \% \mathrm{D} / \mathrm{W}$} & $65 \mathrm{ml}$ & $49.3 \mathrm{ml}$ & $36 \mathrm{ml}$ & $55 \mathrm{ml}$ & $48 \mathrm{ml}$ \\
\hline \multicolumn{2}{|l|}{ Lipid (20\% IVFE) } & 0 & \multicolumn{4}{|c|}{$9.5 \mathrm{ml}(1.9 \mathrm{~g} / 100 \mathrm{ml})$} \\
\hline \multicolumn{2}{|l|}{$\mathrm{MgSO}_{4}(8 \mathrm{mEq} / 2 \mathrm{ml})$} & \multicolumn{5}{|c|}{$0.1 \mathrm{ml}(0.4 \mathrm{mEq} / 100 \mathrm{ml})$} \\
\hline \multicolumn{2}{|c|}{$\begin{array}{l}\text { Potassium phosphorus (KPO) potassium (K) } 1.5 \mathrm{mEq} \text { per } 0.35 \mathrm{ml} \\
\text { Phosphorus (Ph) } 1 \mathrm{mmol} \text { per } 0.35 \mathrm{ml}\end{array}$} & 0 & \multicolumn{4}{|c|}{$0.35 \mathrm{ml}(\mathrm{K}-1.5 \mathrm{mEq} / 100 \mathrm{ml}, \mathrm{Ph}-1 \mathrm{mmol} / 100 \mathrm{ml})$} \\
\hline \multicolumn{2}{|l|}{$\mathrm{NaCl} 2.5 \mathrm{mEq} / \mathrm{ml}$} & $\begin{array}{l}1 \mathrm{ml}(2.5 \\
\mathrm{mEq})\end{array}$ & \multicolumn{3}{|c|}{$1.2 \mathrm{ml}(\mathrm{Nacl}-3 \mathrm{mEq} / 100 \mathrm{ml})$} & $\begin{array}{l}2.4 \mathrm{ml}(6 \\
\mathrm{mEq} / 100 \mathrm{ml})\end{array}$ \\
\hline \multicolumn{2}{|l|}{ Zinc (1 mg/ml) } & \multicolumn{5}{|c|}{$0.3 \mathrm{ml}-300 \mu \mathrm{g}$ per $100 \mathrm{ml}$} \\
\hline \multicolumn{2}{|l|}{ Calcium gluconate $(10 \%)$} & \multicolumn{5}{|c|}{$1.25 \mathrm{ml}(125 \mathrm{mg} / 100 \mathrm{ml})$} \\
\hline \multicolumn{2}{|c|}{$\begin{array}{l}\text { Multivitamins (preferably both lipid and water-soluble as per } \\
\text { concentration) }\end{array}$} & \multicolumn{5}{|l|}{$1 \mathrm{ml}$} \\
\hline \multicolumn{2}{|l|}{ Heparin $(0.5 \mathrm{lU} / \mathrm{ml})$} & \multicolumn{5}{|c|}{$0.1 \mathrm{ml}(0.05$ unit per $100 \mathrm{ml})$} \\
\hline
\end{tabular}

TABLE 2: Standardized parenteral nutrition: volumes and concentration in different categories

*Only for a central line.

**If electrolytes and sugars are normal.

${ }^{* \star *}$ Consider if POCT blood sugar $>200,3-4$ episodes, confirmed by RBS.

${ }^{\star \star \star \star \star}$ Consider serum sodium $<135 \mathrm{ml}$, unable to receive oral sodium. Hypertonic saline/normal saline boluses should be avoided during high sodium $\mathrm{PN}$, \# can be given to patients with hyperkalemia and renal failure.

Consider individualized PN/fluid electrolytes mixture, if a neonate has

Hypoglycemia despite adequate GIR through standard PN

Hypernatremia $>150 \mathrm{mEq} / \mathrm{dl}$ despite adequate fluids

BUN $>50$

Hypermagnesemia (>2.5 mEq/dl)

PNALD (SBR > $2 \mathrm{mg} / \mathrm{dl}$, or direct bilirubin $>20 \%$ of total, SGPT > 50, Gamma GT > 100)

Hyperglycemia despite low glucose PN

Needs fluids through $\mathrm{PN}>160 \mathrm{ml} / \mathrm{kg} /$ day

\section{TABLE 3: Consideration for individualized parenteral nutrition}

PN: parenteral nutrition, PNALD: parenteral nutrition-associated liver disease, GIR: glucose infusion rate, BUN: blood urea nitrogen, SBR: serum bilirubin, SGPT: serum glutamic-pyruvic transaminase. 


\section{Cureus}

\begin{tabular}{|l|l|l|l|}
\hline Twice daily & Daily & $\begin{array}{l}\text { Twice weekly (Monday, } \\
\text { Thursday) }\end{array}$ & Weekly (Monday) \\
\hline $\begin{array}{l}\text { Electrolytes, BUN, creatinine, and other biochemical profile to be } \\
\text { monitored twice daily if }\end{array}$ & $\begin{array}{l}\text { Electrolytes first } 72 \\
\text { hrs }\end{array}$ & $\begin{array}{l}\text { After the first } 72 \mathrm{hrs} \text { of } \\
\text { neonates on PN }\end{array}$ & $\begin{array}{l}\text { Liver function } \\
\text { test }\end{array}$ \\
\hline - Negative fluids balance $(50 \mathrm{ml} / \mathrm{kg} / \mathrm{day})$ & $\begin{array}{l}\text { Calcium, if }<6.5 \\
\mathrm{mg} / \mathrm{dl}\end{array}$ & $\mathrm{BUN}, \mathrm{Cr}$ & $\begin{array}{l}\text { Phosphorus, } \\
\text { calcium }\end{array}$ \\
\hline Anuria $(>12$ hrs after the first $24 \mathrm{hrs})$ & $\begin{array}{l}\text { Magnesium if }<1.4 \\
\mathrm{mg} / \mathrm{dl}\end{array}$ & $\mathrm{CBC}$ for the first week & $\begin{array}{l}\text { Na, } \mathrm{K} \text { once-off } \\
\text { PN }\end{array}$ \\
\hline Receiving high electrolytes fluids & CBC after \\
\hline
\end{tabular}

\section{TABLE 4: Lab monitoring for biochemically and clinically stable infants}

CBC: complete blood count, BUN: blood urea nitrogen, LFTs: liver function tests, SBR: serum bilirubin.

\section{Data analysis}

Data were analyzed using SPSS 26.0. Mean \pm SD was calculated for total time taken for PN calculation, whereas median (IQR) was reported for the number of PN orders per day, number of PN calculations per prescription, calculations, writing, and software time in minutes, number of correction calls received from pharmacy and number of changes required to be done. Independent T-test was applied to assess the statistical difference between the pre-and post-implementation of PN formulation for the total time required for PN calculation, whereas the Mann-Whitney $\mathrm{U}$ test was applied for the rest of the quantitative variables. Level of residency training, calculation error, writing error, and suggested practices were presented with frequency and percentages, and Pearson's chi-square test was applied for assessing the differences. However, the Fisher exact test was used to determine the differences for software error and suggested practices. A P-value of $<0.05$ was considered significant.

\section{Results}

This study was conducted in two phases: pre-implementation and post-implementation. In the first phase, 34 residents, and in the second phase, 48 residents participated in the study.

The PN calculation was required for each ingredient like macronutrients, micronutrients, electrolytes, mineral, fluid volume while adjusting the fluid volume in medication and feeds. Time consumed for all the calculations mentioned above was 10 minutes (5-12) in the pre-implementation phase and 1 minute (0.5-4) in the post-implementation phase with a significant difference ( $\mathrm{p}$-value $<0.0001)$. The time needed in minutes for order writing in pre-implementation was five minutes (3-5), and post-implementation was one minute $(0-2)$ with a p-value of $<0.0001$ that was significant, as shown in Table 5.

\begin{tabular}{|c|c|c|c|c|}
\hline Variables & Pre-implementation, n (\%) & Post-implementation, n (\%) & Combine, n (\%) & P-value \\
\hline Postgraduate residents & 34 & 48 & 82 & \\
\hline \multicolumn{5}{|l|}{ Level of training } \\
\hline R1 & 0 & $14(29.2)$ & $14(17.10)$ & \multirow{4}{*}{$0.0000^{\star * P}$} \\
\hline R2 & $11(32.4)$ & $22(45.8)$ & $33(40.2)$ & \\
\hline R3 & $17(50.0)$ & $6(12.5)$ & $23(28.0)$ & \\
\hline R4 & $6(17.6)$ & $6(12.5)$ & $12(14.6)$ & \\
\hline \multicolumn{5}{|l|}{ PN prescription assessment } \\
\hline Number of PN/day & $4(3-5)$ & $3.5(2-5)$ & $4(3-5)$ & $0.014^{*} \mathrm{M}$ \\
\hline Number of PN calculation/day & $2.5(1-5)$ & $8(2.5-10)$ & $5(1-9)$ & $0.0000^{* * \mathrm{M}}$ \\
\hline Calculation time/mins & $10(5-12)$ & $1(0.5-4)$ & $5(1-10)$ & $0.0000^{* * \mathrm{M}}$ \\
\hline
\end{tabular}




\section{Cureus}

\begin{tabular}{|c|c|c|c|c|}
\hline Writing time/mins & $5(3-5)$ & $1(0-2)$ & $2(0.5-5)$ & $0.0000^{* * \mathrm{M}}$ \\
\hline Software time/mins & $2(2-5)$ & $1(0.5-2.5)$ & $2(1-3)$ & $0.0000^{\star \star} \mathrm{M}$ \\
\hline Total time/mins & $17.1(6.9)$ & $10.5(5.7)$ & $13.3(7.0)$ & $0.0000^{\star \star T}$ \\
\hline Number of correction calls & $1.5(1-3)$ & $1(1-2)$ & $1(1-2)$ & $0.031^{*} \mathrm{M}$ \\
\hline Number of changes & $2(1-2)$ & $1(1-1)$ & $1(1-2)$ & $0.002^{*} \mathrm{M}$ \\
\hline \multicolumn{5}{|l|}{ Calculation error } \\
\hline Never & $6(17.6)$ & $8(16.7)$ & $14(17.1)$ & \multirow{3}{*}{$0.031^{*} \mathrm{P}$} \\
\hline Occasional & $17(50.0)$ & $34(70.8)$ & $51(62.2)$ & \\
\hline Frequent & $11(32.4)$ & $6(12.5)$ & $17(20.7)$ & \\
\hline \multicolumn{5}{|l|}{ Writing error } \\
\hline Never & $11(32.4)$ & $10(20.8)$ & $21(25.6)$ & \multirow{4}{*}{$0.0000^{* * P}$} \\
\hline Occasional & $11(32.4)$ & $19(39.6)$ & $30(36.6)$ & \\
\hline Frequent & $12(35.3)$ & $4(8.3)$ & $16(19.5)$ & \\
\hline Not applicable & 0 & $15(31.3)$ & $15(18.3)$ & \\
\hline \multicolumn{5}{|l|}{ Software error } \\
\hline Never & $10(29.4)$ & $3(6.3)$ & $13(15.9)$ & \multirow{4}{*}{$0.003^{* f}$} \\
\hline Occasional & $15(44.1)$ & $33(68.8)$ & $48(58.5)$ & \\
\hline Frequent & $9(26.5)$ & $7(14.6)$ & $16(19.5)$ & \\
\hline Not applicable & 0 & $5(10.4)$ & $5(6.1)$ & \\
\hline \multicolumn{5}{|c|}{ Level of difficulty in ordering PN } \\
\hline Easy & $12(35.3)$ & 35 (72.9) & $47(57.3)$ & \multirow{3}{*}{$0.001^{* f}$} \\
\hline Moderate & $20(58.8)$ & $13(27.1)$ & $33(40.2)$ & \\
\hline Hard & $2(5.9)$ & 0 & $2(2.4)$ & \\
\hline \multicolumn{5}{|l|}{ Practices } \\
\hline Satisfied/continue & $11(22.9)$ & $28(82.4)$ & $39(47.6)$ & \multirow{2}{*}{$0.0000^{* * P}$} \\
\hline Needs revision & $37(77.1)$ & $6(17.6)$ & $43(52.4)$ & \\
\hline
\end{tabular}

\section{TABLE 5: Pre-and post-implementation assessment}

${ }^{\star} \mathrm{P}$-value $<0.05,{ }^{\star \star} \mathrm{P}$-value $<0.0001$.

T: independent sample T-test, M: Mann-Witney U test, P: Pearson Chi-square, f: Fisher's exact test.

In the pre-implementation phase, the order requires the following three, i.e., concentration and amount of ingredients written on the residents order paper, entered in the pharmacy software template, and then manually written paper shared with pharmacy. In the post-implementation phase, the order requires only one step' in one unit (AKUH); the post-graduate trainee enters a fixed amount of each ingredient in Physician Order Entry (POE) software and in another unit (IHHN) pre-designed pneumonic to be selected in POE for different categories of standard PN. So, time consumption in post-implementation was one minute (0.5-2) than pre-implementation phase $2(2-5)$.

The total time required to do the entire writing process, calculation, and ordering of PN was $17.1 \pm 6.9$, whereas it significantly ( $\mathrm{p}$-value $<0.0001$ ) reduced to $10.5 \pm 5.7$ after implementing PN formulation. Calculation Errors (32\%) and writing errors (35\%) were reduced up to $12 \%$ and $8 \%$, respectively, in the preand post-implementation phase. In the post-implementation phase, order entry errors in POE Software decreased to $15 \%$ compared to frequent (26\%) in the pre-implementation phase. 
In the pre-implementation phase, the individualized (PN) satisfaction level was $22.9 \%$, which was increased to $82 \%$ with SPN (p-value $<0.0001$ ). Similarly, a significant difference was observed in practices as the pharmacy's revision calls were reduced to $17.6 \%$ compared to $77.1 \%$ in the pre-implantation phase with a pvalue of $<0.0001$. Total $59 \%$ of the residents reported difficulty level in ordering prescriptions for individualized PN as moderately hard, and for SPN, $73 \%$ of residents responded to it as easy. The entire process of requesting and formulating standard PN, overall, is much easier and less time-consuming when compared to IPN.

\section{Discussion}

Pakistan has the third-highest number of neonatal deaths globally, with a reported neonatal mortality rate of 49 deaths per 1000 live births and an estimated 298,000 neonatal deaths yearly [15]. With poor maternal and neonatal health policies, incapacitated infrastructure, neonatal healthcare services are severely hampered in Pakistan. Neonatal nutrition services are limited to only a few tertiary care hospitals [16].

PN is an essential element in the care of neonates, particularly premature infants admitted to NICUs [17]. For VLBW babies, early "aggressive" parenteral feeding is now the recommended procedure. The aim of providing early PN to preterm infants is to improve mortality, morbidity, and long-term neurodevelopmental outcomes [18]. Since PN is an intravenous prescription; it is vulnerable to medication errors, where all the calculations are weight-based [19]. With over 50 constituents, PN is one of the most complex medications therapy. Prescription writing, transcription, calculation, and administration are all stages in the PN management process where errors can occur [20]. PN administration also has the potential to cause infectious complications as well as metabolic disturbances [21].

PN is administered under two regimes, the SPN and a much more precise and conventional IPN. IPN lets the physician prescribe a formulation tailor-made for a specific neonate, while SPN offers a more generalized solution to the issue. For neonates with VLBW who are also suffering from severe sickness or a metabolic disorder, IPN is the preferred formulation as it provides specific nutrients for the infant [22]. However, for infants merely needing a quick weight gain, several studies have suggested that SPN would be the superior choice as it promotes better absorption of glucose, amino acids along with calcium and phosphorus in the body $[11,23]$. Neonates in general have a weak immune system and are prone to infections, adding VLBW to the equation only aggravates the condition. SPN helps in decreasing the risk of infections more efficiently than IPN would [24].

PN itself is an expensive therapy, and it requires several additional resources like neonate monitoring, the cost of keeping the child in NICU, and hospital care. IPN further elevates the cost as more precision and care are needed to make the formulation. SPN offers a solution that is cheaper with relatively similar results to IPN for the infant's diet. Studies suggest that SPN decreases the cost of PN therapy by 30-56\% annually as there is no extra cost for materials, inventory-holding, and extra manpower to formulate the composition $[11,25-27]$. Therefore, SPN provides an advantage over IPN for the people of developing countries who can barely afford the cost for treatment of various neonatal health hazards much prevalent.

In many NICUs in Pakistan, PN is provided by individualized solutions prescribed and prepared for each infant rather than standardized stock solutions. This practice was a complex, time-consuming, brainstorming task for related healthcare workers. Therefore, in this study, we implemented the SPN ordering process in NICU to reduce physicians' workload and associated errors and delays. In support of our primary hypothesis, this study found that there was a significant difference observed in the calculation and writing errors ( $p$-value $<0.05$ and $<0.0001$, respectively) after the standardization. Several studies have also shown that IPN is associated with increased medical errors, while SPN formulations have significantly fewer prescription errors in patients $[27,28]$.

Each resident daily wrote around four to five prescriptions in the pre-implementation phase, which required approximately 30 minutes to calculate, prescribe, and request the pharmacy. The pharmacist involved in PN therapy is an essential part of the multidisciplinary nutrition management team [29]. The PN pharmacist required an almost similar time to review and recalculate the requested PN. This used to take around three to four hours, after which the PN technician starts PN formulation. The entire process takes up to six to eight hours altogether. After the implementation of SPN, the time required for ordering PN was also optimized. There was also a significant decrease in time consumption for each PN ordering process (p-value $<0.0001$ ) that ultimately decreased the number of calls back for correction and errors (p-value $<0.05$ ). These results agree with the study highlighting the advantages of SPN for premature neonates [27].

Overall, this implementation was a rewarding experience that helped physicians, pediatrics and neonatology residents, pharmacists, nurses, and PN technicians. Now, residents and physicians can easily place requests for SPN for an infant according to their gestation, age, and biochemical status with volume rate per hour in pharmacy software without needing extensive unnecessary calculations. This strategy also forms part of an approach concerning quality control and good professional practice to prepare PN solutions in our study.

The limitation of this study includes a small sample size; however, we included all the available consenting post-graduate residents working in NICUs in both study centers. Due to the small sample size, advanced 
analysis was not performed; therefore, the effect of confounders was not adjusted. More data are required to assess the contrast of the impact of SPN over IPN on neonatal health and well-being by conducting large intervention-based studies or randomized control trials.

We propose to develop the required range of standardized neonatal PN formulations on a national level. To create the best possible formulations both nutritionally and pharmaceutically, there is a need to gather all available neonatologists, nutritionists, pediatric gastroenterologists, pharmacists, and nurses nationwide. The provision of sufficient nutrition without inducing biochemical derangement is an essential part of neonatal intensive care management. Concerning higher nutritional intake, weight gain, fewer medication errors, and cost of SPN may have advantages over IPN; without causing a significant biochemical disturbance. Therefore, we believe that SPN formulations would have an acceptable nutritional composition, resulting in satisfactory biochemical regulation and development in VLBW infants at various stages of their NICU stay [28].

\section{Conclusions}

The implementation of SPN has revolutionized the overall standard of neonatal care. Our findings show that implementing standardized prescriptions in the NICU has improved medication safety, with the most consistent benefit by reducing medication errors and time management. We deduced that this standardization not only saved time but also decreased the workload on physicians, trainees, pharmacists, PN technicians, and nurses by eliminating previously required repetitive activities and calculations.

\section{Additional Information}

\section{Disclosures}

Human subjects: Consent was obtained or waived by all participants in this study. Interactive Research and Development (IRD) issued approval IRD_IRB_2020_06_004. The IRD-IRB has reviewed the above-referenced study and determined that, as currently described, it was eligible for expedited review and has been approved, as per the following category: Category \#7: Research on individual or group characteristics or behavior (including, but not limited to, research on perception, cognition, motivation, identity, language, communication, cultural beliefs or practices, and social behavior) or research employing survey, interview, oral history, focus group, program evaluation, human factors evaluation, or quality assurance methodologies. Animal subjects: All authors have confirmed that this study did not involve animal subjects or tissue. Conflicts of interest: In compliance with the ICMJE uniform disclosure form, all authors declare the following: Payment/services info: All authors have declared that no financial support was received from any organization for the submitted work. Financial relationships: All authors have declared that they have no financial relationships at present or within the previous three years with any organizations that might have an interest in the submitted work. Other relationships: All authors have declared that there are no other relationships or activities that could appear to have influenced the submitted work.

\section{References}

1. Haschke F, Binder C, Huber-Dangl M, Haiden N: Early-life nutrition, growth trajectories, and long-term outcome. Nestle Nutr Inst Workshop Ser. 2019, 90:107-20. 10.1159/000490299

2. Lau C: Development of suck and swallow mechanisms in infants . Ann Nutr Metab. 2015, 66 Suppl 5:7-14. $10.1159 / 000381361$

3. Bromley PN, Rawlinson E, Harclerode Z, Bennett J: Developmental physiology of the liver, gastrointestinal tract, and renal system. Gregory's Pediatric Anesthesia. Wiley, Hoboken; 2020. 164-90. 10.1002/9781119371533.ch9

4. Tan JB, Boskovic DS, Angeles DM: The energy costs of prematurity and the neonatal intensive care unit (NICU) experience. Antioxidants (Basel). 2018, 7:37. 10.3390/antiox7030037

5. Nakayama DK: The development of total parenteral nutrition. Am Surg. 2017, 83:36-8. 10.1177/000313481708300122

6. Hay WW: Optimizing nutrition of the preterm infant. Zhongguo Dang Dai Er Ke Za Zhi. 2017, 19:1-21. 10.7499/j.issn.1008-8830.2017.01.001

7. White R: Quality parenteral nutrition: an ideal mixed bag. Proc Nutr Soc. 2011, 70:285-92. 10.1017/S0029665111000541

8. Reber E, Messerli M, Stanga Z, Mühlebach S: Pharmaceutical aspects of artificial nutrition. J Clin Med. 2019, 8:2017. 10.3390/jcm8112017

9. Hermanspann T, Schoberer M, Robel-Tillig E, Härtel C, Goelz R, Orlikowsky T, Eisert A: Incidence and severity of prescribing errors in parenteral nutrition for pediatric inpatients at a neonatal and pediatric intensive care unit. Front Pediatr. 2017, 5:149. 10.3389/fped.2017.00149

10. Boullata JI, Gilbert K, Sacks G, et al.: A.S.P.E.N. clinical guidelines: parenteral nutrition ordering, order review, compounding, labeling, and dispensing. JPEN J Parenter Enteral Nutr. 2014, 38:334-77. 10.1177/0148607114521833

11. Yeung MY, Smyth JP, Maheshwari R, Shah S: Evaluation of standardized versus individualized total parenteral nutrition regime for neonates less than 33 weeks gestation. J Paediatr Child Health. 2003, 39:6137. 10.1046/j.1440-1754.2003.00246.x

12. Morgan C, Tan M: Attainment targets for protein intake using standardised, concentrated and individualised neonatal parenteral nutrition regimens. Nutrients. 2019, 11:2167. 10.3390/nu11092167

13. Simmer K, Rakshasbhuvankar A, Deshpande G: Standardised parenteral nutrition. Nutrients. 2013, 5:1058- 
70. 10.3390/nu5041058

14. Bolisetty S, Osborn D, Sinn J, Lui K: Standardised neonatal parenteral nutrition formulations - an Australasian group consensus 2012. BMC Pediatr. 2014, 14:48. 10.1186/1471-2431-14-48

15. Khan A, Kinney MV, Hazir T, et al.: Newborn survival in Pakistan: a decade of change and future implications. Health Policy Plan. 2012, 27 Suppl 3:iii72-87. 10.1093/heapol/czs047

16. Koletzko B, Goulet O, Hunt J, Krohn K, Shamir R: 1. Guidelines on Paediatric Parenteral Nutrition of the European Society of Paediatric Gastroenterology, Hepatology and Nutrition (ESPGHAN) and the European Society for Clinical Nutrition and Metabolism (ESPEN), Supported by the European Society of Paediatric Research (ESPR). J Pediatr Gastroenterol Nutr. 2005, 41 Suppl 2:S1-87. 10.1097/01.mpg.0000181841.07090.f4

17. Jehan I, Harris H, Salat S, et al.: Neonatal mortality, risk factors and causes: a prospective population-based cohort study in urban Pakistan. Bull World Health Organ. 2009, 87:130-8. 10.2471/blt.08.050963.

18. Ehrenkranz RA: Early, aggressive nutritional management for very low birth weight infants: what is the evidence?. Semin Perinatol. 2007, 31:48-55. 10.1053/j.semperi.2007.02.001

19. Lehmann CU, Miller MR: Standardization and the practice of medicine. J Perinatol. 2004, 24:135-6. 10.1038/sj.jp.7211060

20. Flynn EA, Pearson RE, Barker KN: Observational study of accuracy in compounding i.v. admixtures at five hospitals. Am J Health Syst Pharm. 1997, 54:904-12. 10.1093/ajhp/54.8.904

21. Maisonneuve N, Raguso CA, Paoloni-Giacobino A, et al.: Parenteral nutrition practices in hospital pharmacies in Switzerland, France, and Belgium. Nutrition. 2004, 20:528-35. 10.1016/j.nut.2004.03.020

22. Riskin A, Picaud JC, Shamir R: ESPGHAN/ESPEN/ESPR/CSPEN guidelines on pediatric parenteral nutrition: Standard versus individualized parenteral nutrition. Clin Nutr. 2018, 37:2409-17. 10.1016/j.clnu.2018.06.955

23. Lenclen R, Crauste-Manciet S, Narcy P, et al.: Assessment of implementation of a standardized parenteral formulation for early nutritional support of very preterm infants. Eur J Pediatr. 2006, 165:512-8. 10.1007/s00431-006-0124-1

24. Zingg W, Tomaske M, Martin M: Risk of parenteral nutrition in neonates--an overview . Nutrients. 2012, 4:1490-503. 10.3390/nu4101490

25. Petros WP, Shank WA Jr: A standardized parenteral nutrition solution: prescribing, use, processing, and material cost implications. Hosp Pharm. 1986, 21:648-9, 654-6.

26. Maswoswe IJ, Newcomer DR, Quandt CM: Achieving parenteral nutrition cost savings through prescribing guidelines and formulary restrictions. Am J Hosp Pharm. 1987, 44:1376-81.

27. Riskin A, Shiff Y, Shamir R: Parenteral nutrition in neonatology--to standardize or individualize? . Isr Med Assoc J. 2006, 8:641-5.

28. Eleni-dit-Trolli S, Kermorvant-Duchemin E, Huon C, et al.: Early individualised parenteral nutrition for preterm infants. Arch Dis Child Fetal Neonatal Ed. 2009, 94:F152-3. 10.1136/adc.2007.136333

29. Tucker A, Ybarra J, Bingham A, et al.: American Society for Parenteral and Enteral Nutrition (A.S.P.E.N.) standards of practice for nutrition support pharmacists. Nutr Clin Pract. 2015, 30:139-46. $10.1177 / 0884533614550318$ 